\title{
Epidemiological aspects of vector, parasite, and domestic reservoir in areas of recent transmission and no reported human cases of visceral leishmaniasis in Brazil
}

\author{
Fabiana de Oliveira Lara-Silva ${ }^{\mathrm{a}, 1}$, Érika Monteiro Michalsky ${ }^{\mathrm{a}, 1}$, \\ Consuelo Latorre Fortes-Dias ${ }^{\mathrm{b}}$, Vanessa de Oliveira Pires Fiuzac ${ }^{\mathrm{c}}$, \\ José Eduardo Marques Pessanha ${ }^{c}$, Shara Regina-Silva ${ }^{a}$, Daniel Moreira de Avelar ${ }^{\mathrm{a}}$, \\ Maiara Alves Silva ${ }^{a}$, Ana Cristina Vianna Mariano da Rocha Lima ${ }^{a}$, \\ Ailton Junior Antunes da Costa ${ }^{a}$, George Luiz Lins Machado-Coelho ${ }^{\mathrm{d}}$, \\ Edelberto Santos Dias ${ }^{\mathrm{a}, *}$ \\ a Laboratório de Leishmanioses, Centro de Pesquisas René Rachou/Fiocruz, Belo Horizonte, Minas Gerais, Brazil \\ ${ }^{\mathrm{b}}$ Diretoria de Pesquisa e Desenvolvimento, Fundação Ezequiel Dias, Belo Horizonte, Minas Gerais, Brazil \\ ' Secretaria Municipal de Saúde de Belo Horizonte, SMSA/PBH, Brazil \\ d Universidade Federal de Ouro Preto, Minas Gerais, Brazil
}

\section{A R T I C L E I N F O}

\section{Article history:}

Received 24 June 2014

Received in revised form 4 March 2015

Accepted 6 April 2015

Available online 14 April 2015

\section{Keywords:}

Canine visceral leishmaniasis

Lutzomyia longipalpis

Lutzomyia lloydi

cortelezzii complex

Leishmania infantum

Leishmania braziliensis

\begin{abstract}
A B S T R A C T
About $97 \%$ of the human cases of the American visceral leishmaniasis (VL) occur in Brazil. In the last few years, the disease expanded to medium- and large-sized cities, in which surveillance and control actions have been intensified, in an effort to control VL spreading. Our two-year study was conducted in Belo Horizonte, the sixth most populous city in Brazil, which is endemic for VL. We focused in two particular districts of recent transmission of the disease, with no reported human cases and submitted to minor surveillance and control actions. Our aim was to draw an epidemiological profile of the local situation concerning Lutzomyia vector, Leishmania parasites, and the main domestic reservoirs (dogs). Lutzomyia longipalpis comprised $96.5 \%$ of the total phlebotomine sand flies captured and displayed an expressive minimal infection rate by Leishmania infantum (16.7\%). Positive correlations were found between the population densities of $L$. longipalpis, rainfall and temperature. L. infantum was also detected in the cortelezzii complex and, for the first time, in Lutzomyia lloydi. Leishmania braziliensis, an etiological agent of the American cutaneous leishmaniasis, was also identified in L. longipalpis. Among the 1408 dogs serologically tested by standard enzyme-linked and fluorescence immune assays (ELISA/IFA) 3.6\% were positive for VL. L. infantum DNA and Leishmania parasites were identified in $100 \%$ and $72.5 \%$ of the seropositive dogs, respectively. The co-positivity of other diagnostic tests for VL-Leishmania-nested PCR, imprint and myeloculture-was compared to the standard serology. Both symptomatic or asymptomatic dogs displayed an equal average number of positive diagnostic tests for VL. The districts studied display favorable conditions for the rapid spreading of human infection, in terms of $L$. longipalpis population density, and presence of $L$. infantum in both vector and main reservoir.
\end{abstract}

(C) 2015 Elsevier B.V. All rights reserved.

\section{Introduction}

Leishmaniases are present in four out of the five continents and are endemic in 98 countries, with more than 350 million

\footnotetext{
* Corresponding author. Tel.: +55 3133497748.

E-mail address: edel@cpqrr.fiocruz.br (E.S. Dias).

1 Lara-Silva, F.O. and Michalsky, E.M. equally contributed to this study.
}

individuals currently at risk. The visceral form of leishmaniasis (VL) causes large-scale and tenacious epidemics, with high fatality rates (WHO, 2014). About $97 \%$ of the human cases of VL in the Americas occur in Brazil, where more than 70,000 official notifications and more than 3800 deaths were recorded over the last three decades (Werneck, 2010; PAHO, 2013). The epidemiological triad of VL in the country involves Leishmania infantum (syn. Leishmania chagasi) parasites as the etiological agents, Lutzomyia longipalpis phlebotomine sand flies as the main vectors, and dogs (Canis familiaris) 
as the principal domestic reservoirs (Deane and Deane, 1955). It has been observed that canine VL usually precedes human cases of VL (Brazilian Ministry of Health, 2009). Other synantropic reservoirs of VL are foxes (Dusicyon vetulus and Cerdocyon thous), opossums (Didelphis albiventris and Didelphis marsupialis) and rodents (Rattus rattus, Nectomys squamipes, Trichomys apereoides, Proechimys canicollis, Coendu prehensilis) (Quinnell and Courtenay, 2009), although the epidemiological role played by the latter in the urban transmission remains uncertain.

Originally, VL was limited to rural environments; however, in the course of time, the disease underwent a clear epidemiological transition, with increasing incidences in urban areas. In Brazil, it reached medium- and large-sized cities (Brazilian Ministry of Health, 2006). This expansion was due to a set of socioeconomic, physical, and biological factors induced by human activities, which culminated in the adaptation of vectors and reservoirs to urban areas (Lainson, 1989; Rangel and Maurício, 2008).

Most of the extant studies conducted in Brazil do not address the entire epidemiological chain of VL (see Cabrera et al., 2003; Guerra et al., 2004 for exceptions). On the other hand, those that do provide a detailed analysis of the full transmission cycle are not recent, and thus may not reflect the current disease characteristics and prevalence (Deane, 1956; Marzochi et al., 1985). Moreover, most of these studies were performed in endemic regions, where the transmission cycle is fully active and the epidemiological transmission risk (ETR) of VL is high. The actions of the Surveillance and Control Program of VL of the Brazilian Ministry of Health vary according to the local ETR and are generally more intense in the areas with high ETR, where the VL has been established for a number of years. The ETR classification is based on the average number of reported human cases in the last three years $(n)$, and varies from sporadic $(n<2.4)$, to medium $(2.4 \leq n<4.4)$ or intense $(n \geq 4.4)$ (Brazilian Ministry of Health, 2009).

Our study was conducted in Belo Horizonte, the sixth most populous city in Brazil, which is an area of intense ETR for VL, as a whole. However, the average number of human cases varies from district to district and it has been noted that VLis spreading from the Northern to the Southern districts of the city [unpublished data]. The actions of the Surveillance and Control Program of VL concentrate in the districts with intense or medium ETR. Despite the application of systematic control actions-such as the continuous removal of seropositive dogs, early diagnosis/treatment of human cases, and chemical vector control-the VL is still in expansion in the urban areas of Brazil. In the last two quinquennia (2001-2005 and 2006-2010), the prevalence of canine VL remained stable around $18 \%$, despite intensive screening and culling actions. During the same period, the overall number of human cases increased by $41 \%$ [unpublished data]. There is no consensus about the efficacy of these control actions adopted, particularly the canine culling (Dye, 1996; Courtenay et al., 2002; Ribeiro et al., 2013).

The two districts presently studied are located in the South of Belo Horizonte. Despite the presence of canine cases of VL, no human cases have been reported therein. Our aim was to evaluate the current epidemiological status of vector, parasite, and canine reservoir in those districts with recent transmission of VL. Due to their sporadic ETR, they have been submitted to minor actions of the Surveillance and Control Program of VL.

\section{Materials and methods}

\subsection{Ethical procedures}

The present study was approved by the Ethics Committee on Animal Experimentation of Fundação Oswaldo Cruz (CEUA/FIOCRUZ) under the license no. LW-21/11 (protocol no.
P-85/10-2). All the procedures followed the technical norms established by the Federal Board of Veterinary Medicine (CFMV resolution no. 714/2002). Euthanasia was performed at the Zoonosis Control Center in Belo Horizonte, according to the screening-culling procedure of the Program for Visceral Leishmaniasis Control of the Brazilian Ministry of Health. The dog owners were informed of the project objectives and voluntarily signed the Statement of Informed Consent regarding the sample collection for biopsy.

\subsection{Study area}

Our study was developed in two districts of Belo Horizonte $\left(19^{\circ} 55^{\prime} 15^{\prime \prime} \mathrm{S}, 43^{\circ} 56^{\prime} 16^{\prime \prime} \mathrm{W}\right)$, the capital of the Brazilian state of Minas Gerais (Fig. 1). Belo Horizonte occupies an area of $331.4 \mathrm{~km}^{2}$ with population of 2,375,151 inhabitants and an average human development index (HDI) of 0.810 (UNDP, 2013). The two districts, namely Salgado Filho and Miramar, were selected due to the absence of reported human cases of VL. Hence, minor control actions of the Surveillance and Control Program of VL have been applied therein.

\subsection{Entomological survey}

Entomological captures were performed from September 2010 to August 2012, during three consecutive nights from 5:00 pm to 9:00 am, always in the first week of each month, and included nine houses per district (Fig. 1). The houses were selected based on previous canine cases of VL in the neighborhood, in 2010, as well as on environmental conditions that favor the rearing of phlebotomine sand flies such as shadowed areas, presence of domestic animals, and fruit trees. Two HP light traps (Pugedo et al., 2005) were mounted in the peri- and intradomiciles of the houses.

The phlebotomine sand flies of both genders were stored in $70 \%$ ethanol until species identification. The non-engorged females from the third day of capture per month, in particular, were preserved in 6\% DMSO instead. The head and the last three abdominal segments of every female were removed and slide-mounted with Berlese liquid for species identification. The remaining body parts of the females from the third days of capture were used for natural infection assays.

The captured phlebotomine sand flies of both sexes were identified using specific descriptions, taxonomic keys, and comparison with specimens from the Reference Collection of Phlebotomine Sand Flies of the Centro de Pesquisas René Rachou/FIOCRUZ. We adopted the species classification proposed by Young and Duncan (1994). Due to their morphological similarity, Lutzomyia sallesi and L. cortelezzii species were considered as cortelezzii complex. Specimens with missing or incomplete characters that impaired their identification were considered Lutzomyia sp.

\subsection{Climate data}

Monthly climate data (maximum temperature, relative humidity, and total rainfall) were collected at a meteorological station of the Fifth District of the Brazilian Institute of Meteorology, located in Belo Horizonte, Minas Gerais state. Average values of each climate variable and their respective standard deviations were calculated on annual basis. Concerning rainfall, months with precipitation indices higher and lower than the annual average were considered rainy or dry, respectively. For comparison purposes, we normalized the data by taking the highest precipitation value, in each year, as $100 \%$. Similarly, the highest number of $L$. longipalpis specimens captured per year was also taken as $100 \%$ for the respective year. 


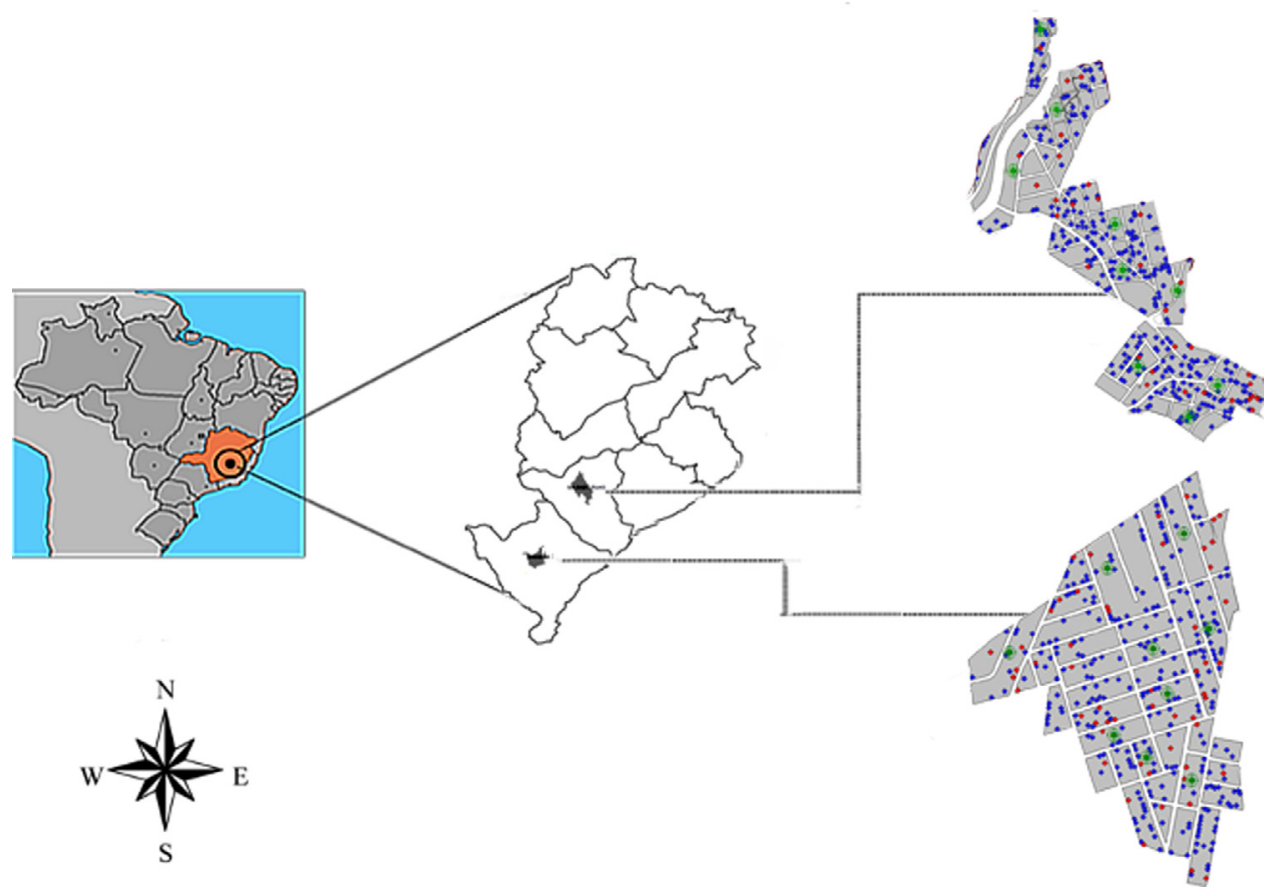

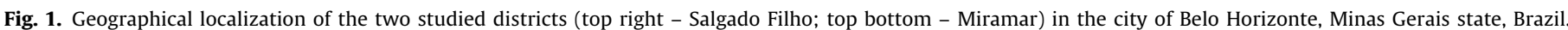

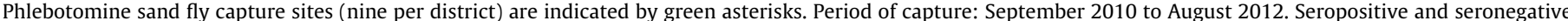

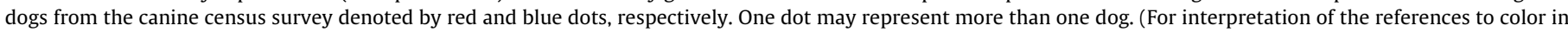
this figure caption, the reader is referred to the web version of this article.)

\subsection{DNA extraction from phlebotomine sand flies and dogs}

Total DNA was extracted from the phlebotomine sand fly females captured every third day per month, using commercial kits (Puragene ${ }^{\circledR}$ Core KitA from QIAGEN). When appropriate, up to ten specimens from the same species, capture site and date were combined as a single test sample for DNA extraction. The reliability of the extraction was verified by the amplification of the IV S6 region from a constitutive gene (cacophony) for Lutzomyia (Lins et al., 2002) and the DNA was used as template in a nested PCR reaction for Leishmania (LnPCR). Negative (no DNA) and positive (DNA from Lutzomyia) controls were run in parallel. Total DNA was also extracted from canine spleen, mesenteric lymph node, and skin by the Cell and Tissue Genomic Prep ${ }^{\mathrm{TM}}$ kit (GE Healthcare). The GFX ${ }^{\mathrm{TM}}$ Genomic Blood DNA Purification kit (GE Healthcare) was used to extract DNA from bone marrow aspirates. The extracted canine DNA served as template in $L n P C R$. All the amplification fragments were analyzed by electrophoresis on $2 \%$ agarose gels followed by ethidium bromide staining and UV visualization.

\subsection{Nested PCR for Leishmania (LnPCR)}

Total DNA from phlebotomine sand flies and dogs was submitted to LnPCR for the SSUrRNA gene that amplifies a conserved fragment for Leishmania (van Eys et al., 1992; Cruz et al., 2002, 2006). Negative (no DNA) and positive (DNA extracted from L. infantum MHOM/BR74/PP75) controls were run in parallel.

\subsection{Minimal infection rate of $\mathrm{L}$. longipalpis by $\mathrm{L}$. infantum}

The minimal infection rate (MRI) by L. infantum was estimated using the formula MRI=number of positive test samples of $L$. longipalpis $\times 100 /$ total number of $L$. longipalpis specimens captured (Paiva et al., 2006).

\subsection{Leishmania identification}

The fragments amplified by LnPCR were purified from agarose gels using the QIAquick Gel Extraction kit (QIAGEN) and submitted to DNA sequencing, in both directions, using the BigDye $^{\circledR}$ Terminator v3.1 Cycle kit and the ABI 3730 analyzer (Life Technologies). The nucleotide segments were aligned with Leishmania braziliensis (M80292.1), L. amazonensis (M80293.1), and $L$. infantum (M81430.1) DNA sequences deposited in the GenBank $^{\circledR}$ database. BioEdit (www.mbio.ncsu.edu/bioedit/bioedit. html), BLAST (www.ncbi.nlm.nih.gov/BLAST), and MacVector NTI ${ }^{\circledR}$ tools were employed in sequence editing and alignment.

\subsection{Collection of canine samples}

A census survey of the local population of dogs was performed in 2011. After collection in filter paper, the blood eluates were tested by immunofluorescence indirect assay (IFA) (Camargo and Rebonato, 1969) and enzyme-linked immunosorbent assay (ELISA) (Voller et al., 1979), using the appropriate kits produced by Biomanguinhos (Fiocruz, RJ, Brazil). Dogs for which absorbance values were equal to or higher than three times the standard deviation of the cutoff value in ELISA and that were positive at $\geq 1: 40$ dilution in IFA were considered seropositive for VL, according to the diagnostic parameters adopted by the Brazilian Ministry of Health. The seropositive dogs were examined by veterinary physicians and classified as asymptomatic or symptomatic, depending on the absence or presence of signs and symptoms suggestive of Leishmania infection. The signs and symptoms observed were lymphoid adenopathy, slight decrease of weight and/or opaque hair, cutaneous alterations (depilation, furfuraceous eczema, ulcers), onychogryphosis, keratoconjunctivitis and rigidity of posterior limbs (Mancianti et al., 1988). Oligosymptomatic cases were considered as a part of the symptomatic group, rather than separately.

After bone marrow aspiration, the seropositive dogs were euthanized at the Zoonosis Control Center in Belo Horizonte. Spleen, 
Table 1

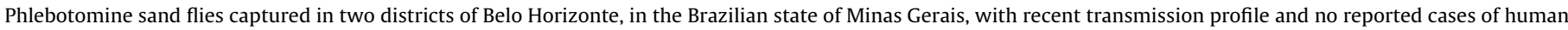
leishmaniasis. Study period: September 2010-August 2012.

\begin{tabular}{|c|c|c|c|c|}
\hline Species & Male & Female & Total & $\%$ \\
\hline cortelezzii complex & 36 & 69 & 105 & 2.02 \\
\hline Lutzomyia intermedia & 4 & 3 & 7 & 0.13 \\
\hline L. ischyracantha & 0 & 2 & 2 & 0.04 \\
\hline L. lloydi & 0 & 1 & 1 & 0.02 \\
\hline L. longipalpis & 4516 & 498 & 5014 & 96.54 \\
\hline L. whitmani & 2 & 5 & 7 & 0.13 \\
\hline Lutzomyia spp. & 23 & 35 & 58 & 1.12 \\
\hline Total & 4581 & 613 & 5194 & 100.0 \\
\hline$\%$ & 88.20 & 11.80 & 100.0 & \\
\hline
\end{tabular}

mesenteric lymph node, and skin fragments were collected and used for preparation of imprints by slide apposition. Slide smears were prepared with bone marrow aspirates. All the slides were examined for the presence of Leishmania parasites, after Giemsa staining. The DNA extracted from canine tissues was used as a template in LnPCR and the bone marrow aspirates were also seeded in NNN/LIT culture medium for Leishmania isolation attempts.

\subsection{Statistical analysis}

The influence of climate variables on the population density of L. longipalpis was evaluated and the results expressed as simple Spearman correlation coefficient $\left(r_{\mathrm{s}}\right)$, for each pair of variables.

The standard ELISA/IFA serological methodology for canine visceral leishmaniasis was taken as reference and the performance of the additional diagnostic tests was evaluated relative to that. Since all the dogs were positive by the standard method, the performance of other diagnostic tests was measured by their precision or accuracy, which express the total of correct classifications. In addition, given that the reference was not the certainty of absence of the disease but a serological result, we used the term co-positivity (that is equivalent to relative sensitivity). The overall co-positivity of the additional diagnostic assays was compared by the chi-square test whereas the co-positivity in the two clinical groups of dogs-symptomatic and asymptomatic-and tissue positivity by LnPCR were compared by the Fisher's exact test. The Mann-Whitney test was employed to compare the number of positive tests among the three tests, in the two clinical groups of dogs.

All the statistical analysis was performed using the Prism 6 software (GraphPad Inc., USA) with 5\% of significance level.

\section{Results}

\subsection{Phlebotomine sand flies survey}

During the study period, a total of 5194 phlebotomine sand flies belonging to six species were captured (Table 1). L. longipalpis was the most prevalent among them. Lutzomyia whitmani and Lutzomyia intermedia-proven vectors of the American cutaneous leishmaniasis (ACL)-were also present, albeit at lower rates. $L$. longipalpis males were more abundant than females, with an overall male/female ratio of 9:1. L. longipalpis specimens were mostly captured $(88.1 \%)$ in the peridomiciles (data not shown).

\subsection{Climate and fluctuation of $\mathrm{L}$. longipalpis population}

During the two years of study, the temperature varied from $24{ }^{\circ} \mathrm{C}$ to $31^{\circ} \mathrm{C}$ with an average of $27.0 \pm 1.6^{\circ} \mathrm{C}$. Humidity ranged between $48.0 \%$ and $78.0 \%$, averaging at $63.0 \pm 7.8 \%$. Major variations occurred in the total precipitation along each year, as expressed by the high standard deviations and the respective variation coefficients: $151.3 \pm 143.8 \mathrm{~mm}(\mathrm{CV}=95.0 \%)$ for the first year

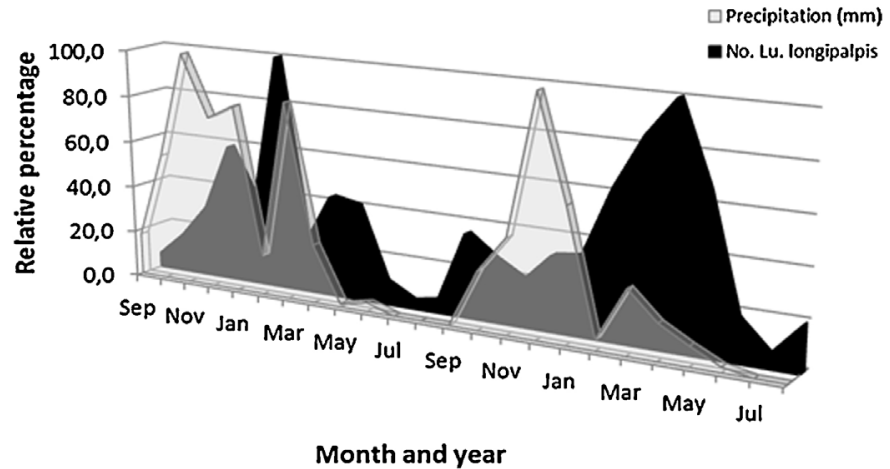

Fig. 2. Pluviometry and population fluctuation of $L$. longipalpis phlebotomine sand flies in the two districts with no reported cases of VL in Belo Horizonte, Minas Gerais, Brazil. Period of study: September 2010 to August 2012.

and $167.9 \pm 216.8 \mathrm{~mm}(\mathrm{CV}=129.1 \%)$ for the second year. Five rainy (October, November, December, January, and March) and seven dry months were readily identified in each year and the population densities of $L$. longipalpis markedly increased after rainfall peaks (Fig. 2).

Positive correlations were found between the monthly population densities of $L$. longipalpis and the three climate variables with correlation coefficients $\left(r_{\mathrm{s}}\right)$ of 0.4177 for rainfall, 0.5430 for temperature and 0.3480 for humidity. However, statistical significance was found only for rainfall $(P$-value $=0.0422)$ and temperature $(P$ value $=0.0061$.

\subsection{Detection of Leishmania DNA in phlebotomine sand flies}

The presence of Leishmania DNA was investigated in 93 test samples prepared with 152 Lutzomyia females. The preparation of pooled samples was applicable for $L$. longipalpis and $L$. whitmani; otherwise, single specimens were employed as test samples. All the test samples displayed the expected $220 \mathrm{bp}$ fragment for the Lutzomyia cacophony gene (data not shown). Leishmania DNA was detected in 29 of the 93 test samples, as indicated by the presence of a $353 \mathrm{bp}$ fragment following $\operatorname{LnPCR}$ (Fig. 3A).

Table 2 summarizes the Leishmania infection ratios and species identification in the Lutzomyia test samples. Positivity for Leishmania sp. means that species identification attempts were unsuccessful. The MRI of $L$. longipalpis by L. infantum was estimated as $16.7 \%$.

\subsection{Canine serology and co-positivity of other diagnostic tests for} $V L$

Among the 1408 dogs tested for VL, 51 (3.6\%) were seropositive by ELISA/IFA. The seropositive dogs were distributed throughout the two districts, with no clusterization (Fig. 1). The dogs were also 


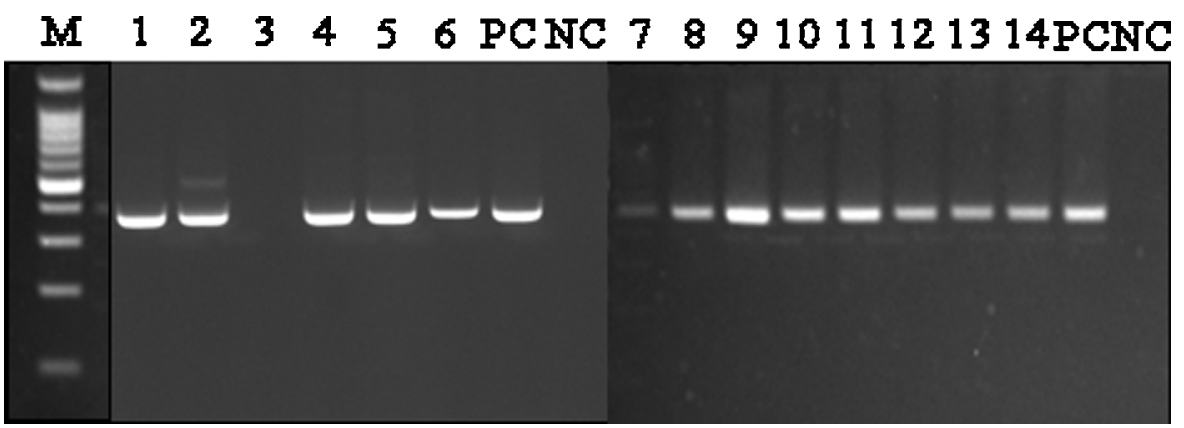

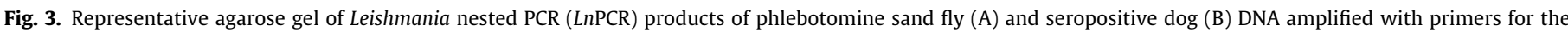

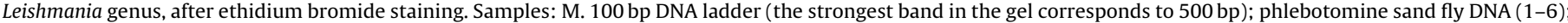
canine DNA (7-14). PC. Positive control [L. braziliensis (MHOM/BR/75/M2903)]. NC: negative control (no DNA).

\section{Table 2}

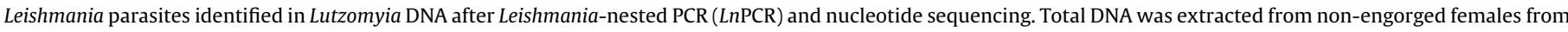

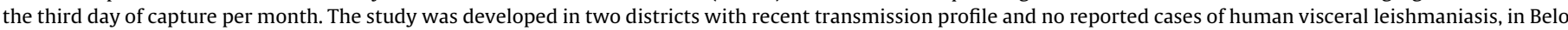
Horizonte, state of Minas Gerais (Brazil). Study period: September 2010 and August 2012.

\begin{tabular}{|c|c|c|c|c|c|c|}
\hline \multirow[t]{2}{*}{ Species } & \multicolumn{2}{|c|}{ Number of females } & \multirow[t]{2}{*}{ Number of test samples } & \multicolumn{3}{|c|}{ Leishmania species in positive samples } \\
\hline & Available & Per test sample & & L. infantum & L. braziliensis & Leishmania sp. \\
\hline cortelezzii complex & 10 & 1 & 10 & 1 & 0 & 1 \\
\hline L. intermedia & 1 & 1 & 1 & 0 & 0 & 0 \\
\hline L. lloydi & 1 & 1 & 1 & 1 & 0 & 0 \\
\hline L. longipalpis & 138 & $1-10$ & 80 & 23 & 2 & 1 \\
\hline L. whitmani & 2 & 2 & 1 & 0 & 0 & 0 \\
\hline Total & 152 & - & 93 & 25 & 2 & 2 \\
\hline
\end{tabular}

tested by one molecular-based ( $L n P C R)$ assay and two parasitebased (imprint and myeloculture) assays. A representative result of $L n P C R$ is shown in Fig. 3B. The number of positive dogs and the positivity rates varied according to the canine tissue analyzed: 51 dogs $(100 \%)$ for the spleen, 41 dogs $(80 \%)$ for the bone marrow,
35 dogs (69\%) for the skin, and 29 dogs (57\%) for the mesenteric lymph node (Fig. 4). While the difference in positivity was significant when lymph node was compared to bone marrow $(P=0.001)$ and to skin $(P=0.031)$, this was not the case for bone marrow comparison to skin. The number of positive dogs by imprint or

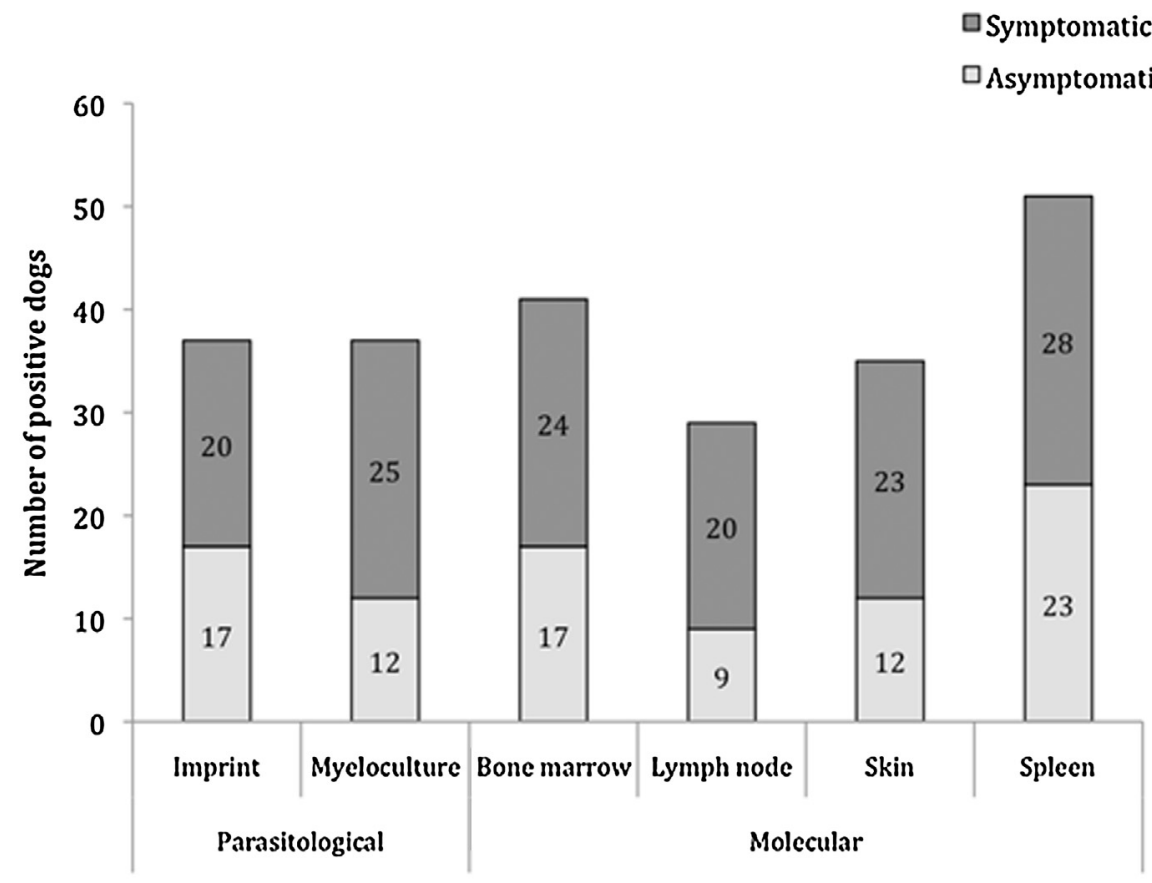

Diagnostic method for visceral leishmaniasis

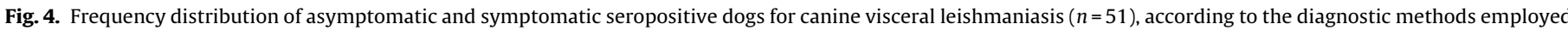

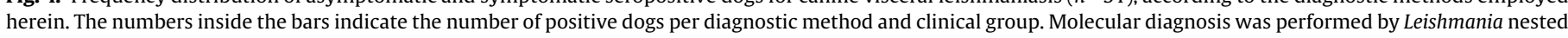
PCR ( LnPCR) with DNA from the tissue samples specified as templates. 
Table 3

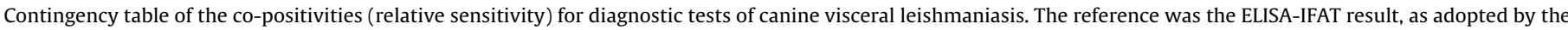

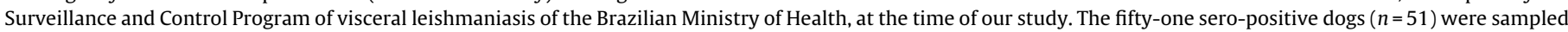
from two districts with recent transmission profile and no human cases of leishmaniasis in Belo Horizonte, in the Brazilian state of Minas Gerais.

\begin{tabular}{|c|c|c|c|c|c|}
\hline \multirow[t]{3}{*}{ Test } & & \multicolumn{4}{|c|}{ IFAT-ELISA } \\
\hline & & \multicolumn{2}{|c|}{ Negative } & \multicolumn{2}{|c|}{ Positive } \\
\hline & & No. & $\%$ & No. & $\%$ \\
\hline \multirow{2}{*}{ LnPCR } & Negative & - & - & 0 & 0 \\
\hline & Positive & - & - & 51 & 100 \\
\hline \multirow{2}{*}{ Imprint } & Negative & - & - & 14 & 27.5 \\
\hline & Positive & - & - & 37 & 72.5 \\
\hline \multirow{2}{*}{ Myeloculture } & Negative & - & - & 14 & 27.5 \\
\hline & Positive & - & - & 37 & 72.5 \\
\hline
\end{tabular}

myeloculture was the same (37 dogs). The co-positivity of these parasite-based methods-72.5\% in both cases-was significantly lower $(P$-value $=0.0002)$, when compared to canine spleen LnPCR (Table 3).

Among the 51 seropositive dogs in our sample, 28 were clinically symptomatic whereas 23 were asymptomatic. LnPCR with canine spleen tissue, in particular, gave $100 \%$ of co-positivity with the ELISA/IFA, for both clinical conditions. The imprint results were not statistically different for the two clinical groups $(P$-value $=1.000)$ (Table 4). Differently, the myeloculture displayed $89.3 \%$ of copositivity for the symptomatic dogs compared to $52.2 \%$ in the asymptomatic ones. These percentages were significantly different with $P$-value $=0.0045$.

The presence of Leishmania assessed by either of the two parasite-based methods was confirmed in $72.5 \%$ of the seropositive dogs (Fig. 5). However, the identified dogs were not necessarily the same in both tests. A combined analysis of the results of the three additional tests showed that 28 dogs (54.9\%) were positive in all three tests, 18 dogs (35\%) were positive by LnPCR and one of the parasite-based tests, and $9.8 \%$ were identified as positive by LnPCR but with no confirmation of the presence of Leishmania parasites (Fig. 5).

The average number of positive tests in the symptomatic canine group was 2.607 with a standard deviation of 0.629 . This value decreased to $2.261 \pm 0.689$ in the asymptomatic group (data not shown). The difference in the total of positive tests, according to the clinical canine group, was not statistically significant $(P-$ value $=0.066$ ).

\subsection{Infecting Leishmania in dogs}

L. infantum was identified as the infecting parasite in the spleen tissue of all the seropositive dogs.

\section{Discussion}

Regarding the phlebotomine sand fly fauna, L. longipalpis-the main vector of American VL-was the predominant species (96.5\%) in our study, thus confirming the high adaptation of this phlebotomine species to urban environments (Barata et al., 2004; Silva et al., 2007; Michalsky et al., 2009, 2011). L. longipalpis was more abundant $(88.1 \%)$ in the peridomicile of the houses, as observed in other studies (Michalsky et al., 2009; Missawa and Dias, 2007; Barata et al., 2013, among others). The predominance of $L$. longipalpis males over females $(\mathrm{M} / \mathrm{F}=9.0)$ was expressive (Michalsky et al., 2009; Ximenes et al., 1999; Souza et al., 2004).

Increased $L$. longipalpis population density was correlated to increased rainfall and temperature, consistently to previous reports (Michalsky et al., 2009; Souza et al., 2004; Dias et al., 2007; Oliveira et al., 2008). This effect may help in planning more effective chemical spraying actions to control L. longipalpis, which is one of the main strategies employed to limit the VL spreading in Brazil (Silva et al., 2007).

The minimal rate of infection (18.8\%) of L. longipalpis by Leishmania was surprisingly high compared to average values reported in the literature (Missawa et al., 2010). However, it is close to that reported before (19\%) for an endemic district for VL, in Belo Horizonte (Saraiva et al., 2010). Mostly (92.0\%) of the infecting Leishmania was $L$. infantum, the etiological vector of VL. The high rate of natural infection by $L$. infantum associated to the expressive population density of $L$. longipalpis indicates very favorable vector conditions for the rapid spreading of VL. L. infantum was also found in the cortelezzii phlebotomine complex which was-together with $L$. braziliensis DNA-reported previously (Saraiva et al., 2009; Carvalho et al., 2008). In addition, we detected L. infantum DNA in L. lloydi, which is a novel finding.

Recently, several reports have been published on the presence of genetic material of etiological agents of cutaneous leishmaniasis in visceral leishmaniasis vectors and vice versa. These findings might be explained by variations in permissivity of the sand fly species to Leishmania infection. L. longipalpis, which was found infected by $L$. braziliensis (present study, Paiva et al., 2010) has been considered a permissive species (reviewed by Kamhawi, 2006). Obviously, vector competence for leishmaniasis is a complex matter and cannot be ascertained solely on the presence of Leishmania DNA in a given phlebotomine species.

The high rate of natural Leishmania infection in L. longipalpis was not followed by equally expressive prevalence of canine visceral leishmaniasis (CVL). The prevalence of CVL varies widely in urban areas (Dantas-Torres et al., 2006; Almeida et al., 2009; Naveda et al., 2006, among others) and there is no minimum prevalence that could be used as a marker of human risk. In previous studies performed in endemic cities of Minas Gerais state, we observed CVL prevalences between $1 \%$ and $2 \%$ in certain districts, with average prevalence around 4.5\% for the whole city (Michalsky et al., 2007; Dias et al., 2011). Districts with no human cases of the VL, showed canine prevalence of $28.3 \%$ (Michalsky et al., 2009), whereas prevalences about $1.5 \%$ were found, independently of the absence or presence human cases of VL (Barata et al., 2004). A variable that was previously shown to correlate with CVL prevalence is vector population density (França-Silva et al., 2005) and in Montes Claros (Monteiro et al., 2005). Those studies, however, were based on monthly population density and CVL prevalence. In conclusion, the transmission scenarios of VL in urban areas are complex, highly heterogeneous and involve a network of variables (Werneck, 2008).

In our study, we did not investigate any other possible synanthropic reservoir for VL. However, Leishmania infection up to $67.7 \%$ and around 25\% were reported for rodents and marsupials, respectively, in Belo Horizonte (Technical notes on Veterinary and Zootechnics, 2012; Marcelino et al., 2011; Schallig et al., 2007). Although further studies will be needed to assess the role played by 
Table 4

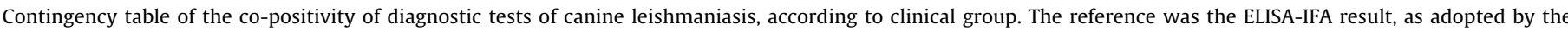

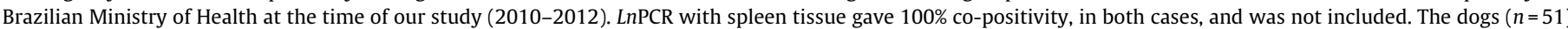
were sampled from two districts with recent transmission profile and no human cases of visceral leishmaniasis in Belo Horizonte, in the Brazilian state of Minas Gerais.

\begin{tabular}{|c|c|c|c|c|c|c|}
\hline Test & & Asymptomatic & & Syn & & $P$-value \\
\hline \multirow{2}{*}{ Imprint } & Negative & 6 & $26.1 \%$ & 8 & $28.6 \%$ & \multirow{2}{*}{1.000} \\
\hline & Positive & 17 & $73.9 \%$ & 20 & $71.4 \%$ & \\
\hline \multirow{2}{*}{ Myeloculture } & Negative & 11 & $47.8 \%$ & 3 & $10.7 \%$ & \multirow{2}{*}{0.0045} \\
\hline & Positive & 12 & $52.2 \%$ & 25 & $89.3 \%$ & \\
\hline
\end{tabular}

other synanthropic reservoirs, they might be important to maintain the zoonotic cycle of VL in Belo Horizonte.

At the time of the present study, the screening and confirmatory tests adopted by the Brazilian Ministry of Health in the canine serological surveys for VL were ELISA and IFA, respectively (Brazilian Ministry of Health, 2006). Although none of the molecular approaches dependent on invasive tissue biopsy would be applicable to canine surveys, our findings confirm that $100 \%$ of the seropositive samples by ELISA/IFA carried L. infantum DNA. Of the 51 sero- and molecularly positive dogs, only $10 \%$ showed no parasitological confirmation by imprint or myeloculture analysis, which are considered the gold standard methods for VL diagnosis. However, $100 \%$ carried Leishmania DNA in their spleen. It is worth noting that spleen was the best tissue sample for PCR amplification, reaching $100 \%$ positivity, while the lowest positivity (57\%) among the four tissues tested was obtained for lymph nodes. Spleen was also shown to be a better choice than lymph node when tissue aspirates were used as samples (Barrouin-Melo et al., 2004). Currently, the Brazilian Ministry of Health replaced the ELISA/IFA set by the rK28based immunochromatography (Dual Path Platform CVL, produced by the Biomanguinhos Institute at Fiocruz, RJ, Brazil) and ELISA, in an effort to increase the specificity and precision in the diagnosis of VL. In a recent comparison of diagnostic tests for VL, by our group, the immunochromatography reached up to $77.3 \%$ of co-positivity compared to ELISA-IFA. Although the canine sample was limited to 44 dogs, those data reinforced that more sensitive and specific tests need to be developed before the efficient diagnosis of canine VL can be performed (Regina-Silva et al., 2014).

Asymptomatic dogs represented $45 \%$ of our seropositive sample. L. infantum DNA was confirmed in all of them. Using parasite-based

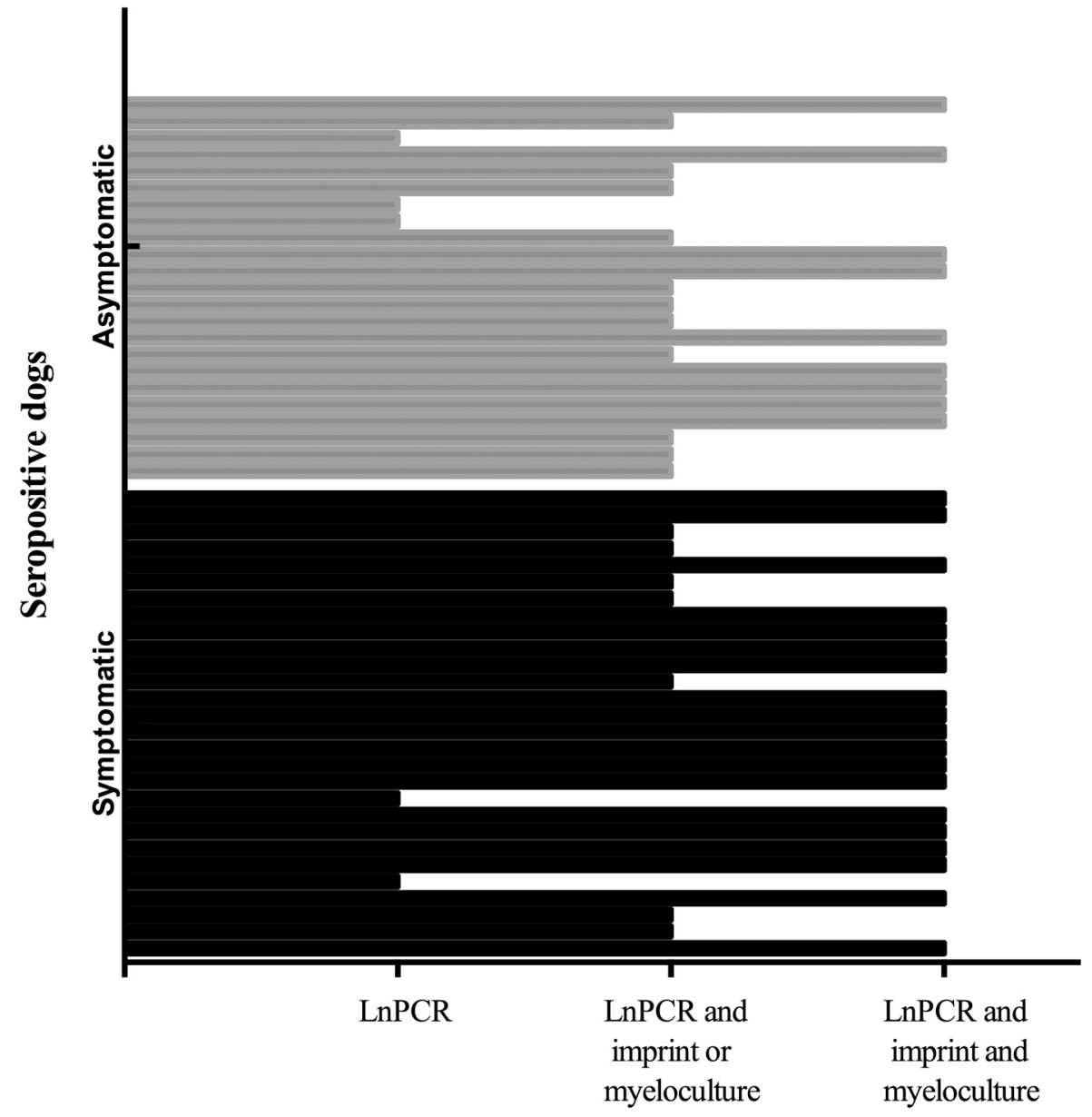

\section{Number of positive diagnostic test}

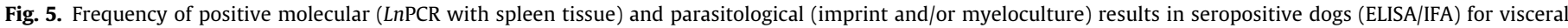

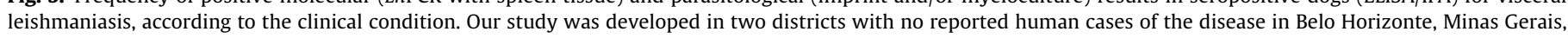
Brazil. Period of study: September 2010 to August 2012. 
methods, $52.2 \%$ were confirmed positive by myeloculture and $73.9 \%$ by imprint. Although previous molecular studies in endemic areas of VL have confirmed that the prevalence of infection is much higher than the number of dogs that actually develop the symptomatic form of the disease (Solano-Gallego et al., 2001; Alvar et al., 2004), those expressive positivity rates indicate the epidemiological importance of asymptomatic dogs in the transmission cycle of VL. Using xenodiagnoses, an infectivity rate of $33 \%$ was reported before for asymptomatic dogs (Michalsky et al., 2007). Hence, the presence of Leishmania in various tissues of this clinical group, particularly in the exposed skin, suggests that the animals may be acting as VL reservoirs (Michalsky et al., 2007; Madeira et al., 2004).

Although our data do not support any prediction of the local VL transmission strength, the districts under study display favorable conditions for the rapid spreading of Leishmania infection, in terms of $L$. longipalpis population density, and presence of $L$. infantum in both vector and main reservoir. The reason why no human cases have been reported, so far, is unknown. The districts studied share the same human occupation and environmental characteristics of any other urban area in Belo Horizonte. The occurrence of human asymptomatic infection, in the studied area, is a possibility. Moreno et al. (2006) reported no human cases of VL in area with 5-10\% of canine VL prevalence, except for eight bad-nourished children that did not developed the disease. Asymptomatic cases with no evolution to acute phase were also observed in the Northeast of Brazil (Jeronimo et al., 2000; Caldas et al., 2002; Gama et al., 2004).

In conclusion, both population density and natural Leishmania infection of vectors as well as CVL prevalence are favorable to outbreaks of human VL, in the districts under study. Even with the actual absence of human cases, control actions are urgently needed to avoid it. As recently pointed out by other authors, more than 30 years after the beginning of the process of visceral leishmaniasis' urbanization, transmission scenarios of VL are still poorly understood and further studies will be needed until we comprehend all the determining variables involved in the transmission of $\mathrm{VL}$ (Belo et al., 2013).

\section{Conflict of interests}

The authors declare that they have no competing interests.

\section{Authors' contributions}

FOLS-phlebotomine experiments, including identification, molecular biology assays, data preparation an article writing; EMM-canine infection experiments, including necropsies, imprints, molecular biology assays, data analysis, article writing; CLFD-sequence alignments, data analysis, article writing and critical review; VOPF-project planning and supervision; JEMP-databank and experimental data analysis; SRS-canine necropsies and tissue biopsies; DMA-parasitological diagnosis; MAS-data collection and organization of entomological and canine databank; ACVMRL-myelocultures; AJAC-entomological captures, specimens preparation and figure preparation; GLLMC-data interpretation and statistical analysis; ESD-project planning and supervision, general data analysis, article review. All the authors approved the submitted version of the article.

\section{Acknowledgements}

We wish to express our gratitude to Dr. França-Silva for collaborating in canine necropsies. We acknowledge the financial support of the Brazilian funding agency Fundação de Amparo à Pesquisa de Minas Gerais (FAPEMIG, grant PPSUS 09/2009).

\section{References}

Almeida, A.B.P.F., Faria, R.P., Pimentel, M.F.A., Dahroug, M.A.A., Turbino, N.C.M.R., Souza, V.R.F., 2009. Seroepidemiological survey of canine leishmaniasis in endemic areas of Cuiabá, State of Mato Grosso. Rev. Soc. Bras. Med. Trop. 42, 156-159.

Alvar, J., Cañavate, C., Molina, R., Moreno, J., Nieto, J., 2004. Canine leishmaniasis. Adv. Parasitol. 57, 1-88.

Barata, R.A., França-Silva, J.C., Costa, R.T., Fortes-Dias, C.L., Silva, J.C., de Paula, E.V., Prata, A., Monteiro, E.M., Dias, E.S., 2004. Phlebotomine sand flies in Porteirinha, an area of American visceral leishmaniasis transmission in the State of Minas Gerais, Brazil. Mem. Inst. Oswaldo Cruz 99, 481-487.

Barata, R.A., Peixoto, J.C., Tanure, A., Gomes, M.E., Apolinário, E.C., Bodevan, E.C. Araujo, H.S., Dias, E.S., Pinheiro, A.C., 2013. Epidemiology of visceral leishmaniasis in a reemerging focus of intense transmission in Minas Gerais state, Brazil. Biomed. Res. Int., 2013.

Barrouin-Melo, S.M., Larangeira, D.F., Trigo, J., Aguiar, P.H.P., dos-Santos, W.L. Pontes-de-Carvalho, L., 2004. Comparison between splenic and lymph node aspirations as sampling methods for the parasitological detection of Leishmania chagasi infection in dogs. Mem. Inst. Oswaldo Cruz 99, 195-197.

Belo, V.S., Werneck, G.L., Barbosa, D.S., Simões, T.C., Nascimento, B.W.L., da Silva, E.S., Struchiner, C.J., 2013. Factors associated with visceral leishmaniasis in the Americas: a systematic review and meta-analysis. PLoS Negl. Trop. Dis. 7, e2182.

Brazilian Ministry of Health, 2006. Manual of Surveillance and Control of Visceral Leishmaniasis, first edition. Ministry of Health, Brasilia, Brazil.

Brazilian Ministry of Health, 2009. Guide of Epidemiological Surveillance, seventh edition. Ministry of Health, Brasilia, Brazil.

Cabrera, M.A.A., Paula, A.A., Camacho, L.A.B., Marzochi, M.C.A., Xavier, S.C., da Silva, A.V.M., Jansen, A.M., 2003. Canine visceral leishmaniasis in Barra de Guaratiba, Rio de Janeiro, Brazil: assessment of risk factors. Rev. Inst. Med. Trop. São Paulo 45, 79-83.

Caldas, A.J.M., Costa, J.M.L., Silva, A.A.M., Vinhas, V., Barral, A., 2002. Risk factors associated with asymptomatic infection by Leishmania chagasi in north-east Brazil. Trans. R. Soc. Trop. Med. Hyg. 96, 21-28.

Camargo, M.E., Rebonato, C., 1969. Cross-reactivity in fluorescence tests for Trypanosoma and Leishmania antibodies. A simple inhibition procedure to ensure specific results. Am. J. Trop. Med. Hyg. 18, 500-505.

Carvalho, G.M., Andrade Filho, J.D., Falcão, A.L., Rocha Lima, A.C., Gontijo, C.M., 2008. Naturally infected Lutzomyia sand flies in a Leishmania-endemic area of Brazil. Vector-Borne Zoonotic Dis. 8, 407-414.

Courtenay, O., Quinnell, R.J., Garcez, L.M., Shaw, J.J., Dye, C., 2002. Infectiousness in a cohort of Brazilian dogs: why culling fails to control visceral leishmaniasis in areas of high transmission. J. Infect. Dis. 186, 1314-1320.

Cruz, I., Cañavate, C., Rubio, J.M., Morales, M.A., Chicarro, C., Laguna, F., JiménezMejías, M., Sirera, G., Videla, S., Alvar, J., 2002. A nested polymerase chain reaction (Ln-PCR) for diagnosing and monitoring Leishmania infantum infection in patients co-infected with human immunodeficiency virus. Trans. R. Soc. Trop. Med. Hyg. 96, 185-189.

Cruz, I., Chicarro, C., Nieto, J., Bailo, B., Cañavate, C., Figueras, M.C., Alvar, J., 2006. Comparison of new diagnostic tools for management of pediatric Mediterranean visceral leishmaniasis. J. Clin. Microbiol. 44, 2343-2347.

Dantas-Torres, F., Brito, M.E.F., Brandão-Filho, S.P., 2006. Seroepidemiological survey on canine leishmaniasis among dogs from an urban area of Brazil. Vet. Parasitol. 140, 54-60.

Deane, L.M., 1956. Leishmaniose visceral no Brasil: estudos sobre reservatórios e transmissores realizados no Estado do Ceará (Visceral leishmaniasis in Brazil: studies on reservoirs and transmitters conducted in the state of Ceará). Serviço Nacional de Educação Sanitária.

Deane, L.M., Deane, M.P., 1955. Observações preliminares sobre a importância comparativa do homem, do cão e da raposa (Lycalopex vetulus) como reservatórios da Leishmania donovani, em área endêmica de calazar no Ceará (Preliminary observations on the comparative importance of man, dog and fox (Lycalopex vetulus) as reservoirs of Leishmania donovani in an endemic area of leishmaniasis in Ceará). O Hospital 48, 61-76.

Dias, E.S., França-Silva, J.C., da Silva, J.C., Monteiro, E.M., de Paula, K.M., Gonçalves, C.M., Barata, R.A., 2007. Sandflies (Diptera: Psychodidae) in an outbreak of cutaneous leishmaniasis in the State of Minas Gerais. Rev. Soc. Bras. Med. Trop. 40, 49-52.

Dias, E.S., Regina-Silva, S., França-Silva, J.C., Paz, G.F., Michalsky, É.M., Araújo, S.C. Valadão, J.L., Lara-Silva, F.O.L., Oliveira, F.S., Pacheco, R.S., Fortes-Dias, C.L., 2011. Eco-epidemiology of visceral leishmaniasis in the urban area of Paracatu, state of Minas Gerais, Brazil. Vet. Parasitol. 176, 101-111.

Dye, C., 1996. The logic of visceral leishmaniasis control. Am. J. Trop. Med. Hyg. 55, $125-130$.

França-Silva, J.C., Barata, R.A., da Costa, R.T., Monteiro, E.M., Machado-Coelho, G.L., Vieira, E.P., Prata, A., Mayrink, W., Nascimento, E., Fortes-Dias, C.L., Silva, J.C., Dias, E.S., 2005. Importance of Lutzomyia longipalpis in the dynamics of transmission of canine visceral leishmaniasis in the endemic area of Porteirinha Municipality, Minas Gerais, Brazil. Vet. Parasitol. 131, 213-220.

Gama, M.E.A., Costa, J.M.L., Gomes, C.M.C., Corbett, C.E.P., 2004. Subclinical form of the American visceral leishmaniasis. Mem. Inst. Oswaldo Cruz 99, 889-893.

Guerra, J.A.O., Barros, M.L.B., Fé, N.F., Guerra, M.V.F., Castellon, E., Paes, M.G., Sherlock, I.A., 2004. Visceral leishmaniasis among Indians of the State of Roraima, Brazil: clinical and epidemiologic aspects of the cases observed from 1989 to 1993 . Rev. Soc. Bras. Med. Trop. 37, 305-311. 
Jeronimo, S.M., Teixeira, M.J., de Queiroz Sousa, A., Thielking, P., Pearson, R.D., Evans, T.G., 2000. Natural history of Leishmania (Leishmania) chagasi infection in Northeastern Brazil: long-term follow-up. Clin. Infect. Dis. 30, 608-609.

Kamhawi, S., 2006. Phlebotomine sand flies and Leishmania parasites: friends or foes? Trends Parasitol. 22, 439-445.

Lainson, R., 1989. Demographic changes and their influence on the epidemiology of the American leishmaniases. In: Michael, W.S. (Ed.), Demography and VectorBorne Diseases. CRC Press, Florida, p. 85.

Lins, R.M.M.A., Oliveira, S.G., Souza, N.A., de Queiroz, R.G., Justiniano, S.C.B., Ward, R.D., Kyriacou, C.P., Peixoto, A.A., 2002. Molecular evolution of the cacophony IVS6 region in sandflies. Insect Mol. Biol. 11, 117-122.

Madeira, M.F., Schubach, A.O., Schubach, T.M.P., Leal, C.A., Marzochi, M.C.A., 2004. Identification of Leishmania (Leishmania) chagasi isolated from healthy skin of symptomatic and asymptomatic dogs seropositive for leishmaniasis in the municipality of Rio de Janeiro, Brazil. Braz. J. Infect. Dis. 8, 440-444.

Mancianti, F., Gramiccia, M., Gradoni, L., Poeri, S., 1988. Studies on canine leishmaniasis control. 1. Evolution of infection of different clinical forms of canine leishmaniasis following antimonial treatment. Trans. R. Soc. Trop. Med. Hyg. 82, 566-567.

Marcelino, A.P., Ferreira, E.C., Avendanha, J.S., Costa, C.F., Chiarelli, D., Almeida, G., Moreira, E.C., Leite, R.C., Reis, J.K.P., Gontijo, C.M., 2011. Molecular detection of Leishmania braziliensis in Rattus norvegicus in an area endemic for cutaneous leishmaniasis in Brazil. Vet. Parasitol. 183, 54-58

Marzochi, M.C.A., Coutinho, S.G., de Souza, W.J.S., de Toledo, L.M., Grimaldi Jr., G., Momem, H., Pacheco, R.S., Sabroza, P.C., de Souza, M.A., Rangel Jr., F.B., Tramontano, N.C., 1985. Canine visceral leishmaniasis in Rio de Janeiro, Brazil: Clinical, parasitological, therapeutical and epidemiological findings (1977-1983). Mem. Inst. Oswaldo Cruz 80, 349-357.

Michalsky, E.M., Rocha, M.F., da Rocha Lima, A.C.V.M., França-Silva, J.C., Pires, M.Q., Oliveira, F.S., Pacheco, R.S., Santos, S.L., Barata, R.A., Romanha, A.J., Fortes-Dias, C.L., Dias, E.S., 2007. Infectivity of seropositive dogs, showing different clinical forms of leishmaniasis, to Lutzomyia longipalpis phlebotomine sand flies. Vet. Parasitol. 147, 67-76.

Michalsky, E.M., França-Silva, J.C., Barata, R.A., Lara-Silva, F.O., Loureiro, A.M.F., Fortes-Dias, C.L., Dias, E.S., 2009. Phlebotominae distribution in Janaúba, an area of transmission for visceral leishmaniasis in Brazil. Mem. Inst. Oswaldo Cruz 104, 56-61.

Michalsky, E.M., Guedes, K.S., Lara-Silva, F.O., França-Silva, J.C., Dias, C.L., Barata, R.A., Dias, E.S., 2011. Natural infection with Leishmania infantum chagasi in Lutzomyia (Lutzomyia) longipalpis (Diptera: Psychodidae) sandflies captured in the municipality of Janaúba, State of Minas Gerais, Brazil. Rev. Soc. Bras. Med. Trop. 44, 58-62

Missawa, N.A., Dias, E.S., 2007. Phlebotomine sand flies (Diptera: Psychodidae) in the municipality of Várzea Grande: an area of transmission of visceral leishmaniasis in the state of Mato Grosso, Brazil. Mem. Inst. Oswaldo Cruz 102. 913-918.

Missawa, N.A., Michalsky, É.M., Fortes-Dias, C.L., Santos Dias, E., 2010. Lutzomyia longipalpis naturally infected by Leishmania (L.) chagasi in Várzea Grande, Mato Grosso State, Brazil, an area of intense transmission of visceral leishmaniasis. Cad. Saude Publica 26, 2414-2419.

Monteiro, E.M., Silva, J.C.F.D., Costa, R.T.D., Costa, D.C., Barata, R.A., Paula, E.V.D., Machado-Coelho, G.L.L., Rocha, M.F., Fortes-Dias, C.L., Dias, E.S., 2005. Visceral leishmaniasis: study on phlebotomine and canine infection in Montes Claros, Minas Gerais. Rev. Soc. Bras. Med. Trop. 38, 147-152.

Moreno, E.C., Melo, M.N., Lambertucci, J.R., Serufo, J.C., Andrade, A.S., Antunes, C.M.F., Genaro, O., Carneiro, M., 2006. Diagnosing human asymptomatic visceral leishmaniasis in an urban area of the State of Minas Gerais, using serological and molecular biology techniques. Rev. Soc. Bras. Med. Trop. 39, 421-427.

Naveda, L.A.B., Moreira, E.C., Machado, J.G., Moraes, J.R.C., Marcelino, A.P., 2006. Epidemiologic aspects of canine visceral leishmaniasis in Pedro Leopoldo district, Minas Gerais, 2003. Arq. Bras. Med. Vet. Zootech. 58, 988-993.

Oliveira, A.G., Galati, E.A., Fernandes, C.E., Dorval, M.E., Brazil, R.P., 2008. Seasonal variation of Lutzomyia longipalpis (Lutz \& Neiva, 1912) (Diptera: Psychodidae: Phlebotominae) in endemic area of visceral leishmaniasis, Campo Grande, state of Mato Grosso do Sul, Brazil. Acta Trop. 105, 55-61.

Pan American Health Organization, 2013. Report Leishmaniases No 1-2013, April http://www.paho.org/hq/index.php?option=com_docman\&task=doc view\&gid=21608\&itemid=270\&lang=es (accessed on 04.12.13).
Paiva, B.R., Secundino, N.F.C., Nascimento, J.C., Pimenta, P.F.P., Galati, E.A.B., Junior, H.F., Malafronte, R.S., 2006. Detection and identification of Leishmania species in field-captured phlebotomine sandflies based on mini-exon gene PCR. Acta Trop. 99, 252-259.

Paiva, B.R., Oliveira, A.G., Dorval, M.E., Galati, E.A., Malafronte, R.S., 2010. Speciesspecific identification of Leishmania in naturally infected sand flies captured in Mato Grosso do Sul State, Brazil. Acta Trop. 115, 126-130.

Pugedo, H., Barata, R.A., França-Silva, J.C., Silva, J.C., Dias, E.S., 2005. HP: an improved model of suction light trap for the capture of small insects. Rev. Soc. Bras. Med. Trop. 38, 70-72.

Quinnell, R.J., Courtenay, O., 2009. Transmission, reservoir hosts and control of zoonotic visceral leishmaniasis. Parasitology 136, 1915-1934.

Rangel, E.F., Maurício, L.V., 2008. Lutzomyia longipalpis (Diptera, Psychodidae, Phlebotominae) and urbanization of visceral leishmaniasis in Brazil. Cad. Saude Publica 24, 2948-2952.

Regina-Silva, S., Fortes-Dias, C.L., Michalsky, É.M., França-Silva, J.C., Quaresma P.F., da Rocha Lima, A.C., Teixeira-Neto, R.G., Dias, E.S., 2014. Evaluation of parasitological examination, kDNA polymerase chain reaction and rK39-based immunochromatography for the diagnosis of visceral leishmaniasis in seropositive dogs from the screening-culling program in Brazil. Rev. Soc. Bras. Med. Trop. 47, 462-468.

Ribeiro, V.M., da Silva, S.M., Menz, I., Tabanez, P., dos Santos Nogueira, F., Werkhaüser, M., Fonseca, A.L.S., Dantas-Torres, F., 2013. Control of visceral leishmaniasis in Brazil: recommendations from Brasileish. Parasit. Vectors 6, 8.

Saraiva, L., Carvalho, G.M., Gontijo, C.M., Quaresma, P.F., Lima, A.C., Falcão, A.L., Andrade Filho, J.D., 2009. Natural infection of Lutzomyia neivai and Lutzomyia sallesi (Diptera: Psychodidae) by Leishmania infantum chagasi in Brazil. J. Med. Entomol. 46, 1159-1163.

Saraiva, L., Andrade Filho, J.D., Silva, S.O., Andrade, A.S., Melo, M.N., 2010. The molecular detection of different Leishmania species within sand flies from a cutaneous and visceral leishmaniasis sympatric area in Southeastern Brazil. Mem. Inst. Oswaldo Cruz 105, 1033-1039.

Schallig, H.D., da Silva, E.S., van der Meide, W.F., Schoone, G.J., Gontijo, C.M., 2007. Didelphis marsupialis (common opossum): a potential reservoir host for zoonotic leishmaniasis in the metropolitan region of Belo Horizonte (Minas Gerais, Brazil). Vector-Borne Zoonotic Dis. 7, 387-393.

Silva, J.G.D., Werneck, G.L., Cruz, M.S.P., Costa, C.H.N., Mendonça, I.L., 2007. Natural infection of Lutzomyia longipalpis by Leishmania sp. in Teresina, Piauí State Brazil. Cad. Saude Publica 23, 1715-1720.

Solano-Gallego, L., Morell, P., Arboix, M., Alberola, J., Ferrer, L., 2001. Prevalence of Leishmania infantum infection in dogs living in an area of canine Leishmaniasis endemicity using PCR on several tissues and serology. J. Clin. Microbiol. 39, 560-563.

Souza, C.M., Pessanha, J.E., Barata, R.A., Monteiro, E.M., Costa, D.C., Dias, E.S., 2004 Study on phlebotomine sand fly (Diptera: Psychodidae) fauna in Belo Horizonte, state of Minas Gerais, Brazil. Mem. Inst. Oswaldo Cruz 99, 795-803.

Technical notes on Veterinary and Zootechnics, 2012. Teaching and Research Foundation in Veterinary Medicine and Zootechnics. FEP MZV Publishing house.

United Nations Development Programme. Brazil. http://www.pnud.org.br/ (accessed 11.12.13)

van Eys, G.J.J.M., Schoone, G.J., Kroon, N.C.M., Ebeling, S.B., 1992. Sequence analysis of small subunit ribosomal RNA genes and its use for detection and identification of Leishmania parasites. Mol. Biochem. Parasitol. 51, 133-142.

Voller, A., Bidwell, D.E., Barlett, A., 1979. The enzyme linked immunosorbent assay (ELISA). A guide with abstracts of microplate applications. Guersney, Great Britain.

Werneck, G.L., 2008. Forum: geographic spread and urbanization of visceral leishmaniasis in Brazil. Introduction. Cad. Saude Publica 24, 2937-2940.

Werneck, G.L., 2010. Geographic spread of visceral leishmaniasis in Brazil. Cad. Saude Publica 26, 644-645.

World Health Organization, 2014 http://www.who.int/leishmaniasis/epidemic/ response_more/en/index.html (accessed 28.01.14).

Ximenes, M.F.F.M., Souza, M.F., Castellón, E.G., 1999. Density of sand flies (Diptera: Psychodidae) in domestic and wild animal shelters in an area of visceral Leishmaniasis in the State of Rio Grande do Norte, Brazil. Mem. Inst. Oswaldo Cruz 94, 427-432.

Young, D.G., Duncan, M.A., 1994. Guide to the identification and geographic distribution of Lutzomyia sand flies in Mexico, the West Indies, Central and South America (Diptera: Psychodidae). Mem. Am. Entomol. Inst. 54, 1-881. 